\title{
Treatment of noninfectious posterior uveitis with dexamethasone intravitreal implant
}

\author{
This article was published in the following Dove Press journal: \\ Clinical Ophthalmology \\ 3 December 2010 \\ Number of times this article has been viewed
}

\section{Jane S Myung \\ Grant D Aaker \\ Szilárd Kiss}

Department of Ophthalmology,

Weill Cornell Medical Center,

New York, NY, USA
Correspondence: Szilárd Kiss

Department of Ophthalmology,

Weill Cornell Medical Center, I 305

York Avenue, I I th Floor, New York,

NY I002I, USA

Tel + I 646-962-22I7

Fax +I 646-962-0609

Email szk700I@med.cornell.edu
Purpose: To report our experience with dexamethasone $0.7 \mathrm{mg}$ sustained-release intravitreal implant (Ozurdex ${ }^{\circledR}$; Allergan, Inc, Irvine, CA) in noninfectious posterior uveitis.

Methods: A retrospective chart review of patients with noninfectious uveitis treated with sustained-release dexamethasone $0.7 \mathrm{mg}$ intravitreal implant was performed. Complete ophthalmic examination including signs of inflammatory activity, visual acuity, fundus photography, fluorescein angiography, optical coherence tomography, and tolerability of the implant were assessed.

Results: Six eyes of 4 consecutive patients treated with a total of 8 dexamethasone $0.7 \mathrm{mg}$ sustained-release intravitreal implants for posterior noninfectious uveitis were included. Two patients presented with unilateral idiopathic posterior uveitis; 2 patients had bilateral posterior uveitis, one secondary to sarcoidosis and the other to Vogt-Koyanagi-Harada syndrome. All eyes showed clinical and angiographic evidence of decreased inflammation following implant placement. Mean follow-up time post-injection was 5.25 months. Four eyes received 1 and 2 eyes received 2 Ozurdex implants during the follow-up period. The duration of effect of the implant was 3 to 4 months. No serious ocular or systemic adverse events were noted during the follow-up period.

Conclusions: In patients with noninfectious posterior uveitis, sustained-release dexamethasone $0.7 \mathrm{mg}$ intravitreal implant may be an effective treatment option for controlling intraocular inflammation.

Keywords: corticosteroids, dexamethasone implant, Ozurdex, uveitis

\section{Introduction}

The mainstay of treatment for noninfectious uveitis remains corticosteroids. Regional steroids have the advantage of minimizing systemic side effects; however, local side effects can include increased intraocular pressure, cataract, and sterile and infectious endophthalmitis. ${ }^{1,2}$

Dexamethasone has potent anti-inflammatory properties with a favorable side-effect profile. ${ }^{3-5}$ Previous studies demonstrated that dexamethasone in a biodegradable drug delivery system (Ozurdex ${ }^{\circledR}$; Allergan Inc, Irvine, California, USA) can improve visual acuity (BCVA) and macular thickness in a variety of settings. ${ }^{3-5}$ Here, we describe our experience with treating noninfectious posterior uveitis with the Ozurdex $0.7 \mathrm{mg}$ dexamethasone intravitreal implant.

\section{Materials and methods}

A retrospective chart review of patients treated with Ozurdex for noninfectious posterior uveitis was undertaken with IRB approval of Weill Cornell Medical College. Included 
Table I Baseline demographics, diagnosis and examination findings of all patients with total follow-up period and final visual acuity outcomes

\begin{tabular}{|c|c|c|c|c|c|c|c|c|c|c|}
\hline Patient & Age & Sex & Diagnosis & $\begin{array}{l}\text { Baseline } \\
\text { BVCA }\end{array}$ & FA & OCT & $\begin{array}{l}\text { Prior } \\
\text { treatment }\end{array}$ & $\begin{array}{l}\text { No. } \\
\text { Ozurdex }\end{array}$ & $\begin{array}{l}\text { Total } \\
\text { follow-up } \\
\text { (months) }\end{array}$ & $\begin{array}{l}\text { Final } \\
\text { BCVA }\end{array}$ \\
\hline $\mathrm{I}$ & 30 & $\mathrm{~F}$ & Sarcoidosis & $20 / 20 \mathrm{OU}$ & $\begin{array}{l}\text { Disc and } \\
\text { perivascular } \\
\text { leakage }\end{array}$ & No CME & $\begin{array}{l}\text { Prednisone } \\
60 \mathrm{mg} \text { and } \\
\text { STT }\end{array}$ & 100 & 600 & $20 / 20 \mathrm{OU}$ \\
\hline 2 & 49 & $M$ & $\begin{array}{l}\text { Vogt-Koyanagi- } \\
\text { Harada }\end{array}$ & $\begin{array}{l}\text { Count fingers } \\
\text { OU }\end{array}$ & $\begin{array}{l}\text { Hyperfluorescent } \\
\text { dots at level of } \\
\text { RPE with leakage } \\
\text { into serous RDs }\end{array}$ & $\begin{array}{l}\text { Serous } \\
\text { RDs }\end{array}$ & STT & $\begin{array}{l}1 \mathrm{OD} \\
2 \mathrm{OS}\end{array}$ & $\begin{array}{l}2 \mathrm{OD} \\
4 \mathrm{OS}\end{array}$ & $\begin{array}{l}20 / 20 \text { OD } \\
20 / 30 \text { OS }\end{array}$ \\
\hline 3 & 29 & $\mathrm{~F}$ & $\begin{array}{l}\text { Idiopathic retinal } \\
\text { vasculitis }\end{array}$ & $\begin{array}{l}\text { Hand motion } \\
\text { OS }\end{array}$ & $\begin{array}{l}\text { Extensive disc, } \\
\text { perivascular, and } \\
\text { parafoveal leakage }\end{array}$ & CME & None & 2 & 8 & $20 / 40$ OS \\
\hline 4 & 81 & $\mathrm{~F}$ & $\begin{array}{l}\text { Idiopathic } \\
\text { anterior NG } \\
\text { uveitis with CME }\end{array}$ & $20 / 50$ OD & $\begin{array}{l}\text { Late parafoveal } \\
\text { leakage }\end{array}$ & CME & $\begin{array}{l}\text { Topical } \\
\text { prednisolone } \\
\text { acetate }\end{array}$ & I & 4 & $20 / 50 \mathrm{OD}$ \\
\hline
\end{tabular}

Abbreviations: BCVA, best-corrected visual acuity Snellen equivalent in the study eye; CME, cystoid macular edema; STT, sub-Tenon's triamcinolone; RD, retinal detachment; NG, nongranulomatous; OD, right eye; OS, left eye; OU, both eyes; OCT, optical coherence tomography; FA, fluorescein angiography.

were demographics, etiology of inflammation, BCVA, prior therapies, examination, and adverse events.

Patients underwent a comprehensive examination including optical coherence tomography (OCT), fluorescein angiography (FA), and fundal photography. A systemic work-up included laboratory and radiographic imaging for infectious and noninfectious etiologies. Ozurdex was administered in accordance with the manufacturer's instructions using the 22-gauge applicator device (Ozurdex package http://www.allergan. com/assets/pdf/ozurdex_pi.pdf).

\section{Results}

Six eyes of 4 patients were included. Patient demographics, diagnosis, and examination findings are summarized in Table 1. Mean follow-up time post-injection was 5.25 months (range 2-8 months). No serious systemic or ocular treatment-related adverse events occurred. Subconjunctival hemorrhage occurred at the injection site. Intraocular pressures remained unchanged in all eyes during follow-up.

\section{Patient I}

A 30-year-old female presented with papillitis and retinal vasculitis of the left eye (OS). A work-up revealed a diagnosis of sarcoidosis. Despite $60 \mathrm{mg}$ of oral prednisone and 1 sub-Tenon's triamcinolone injection OS, there was persistent inflammation. Similar findings developed in the right eye (OD). Ozurdex was administered in both eyes (OU). Six months post-Ozurdex and off oral steroids, the patient shows no signs of inflammation (Figure 1).

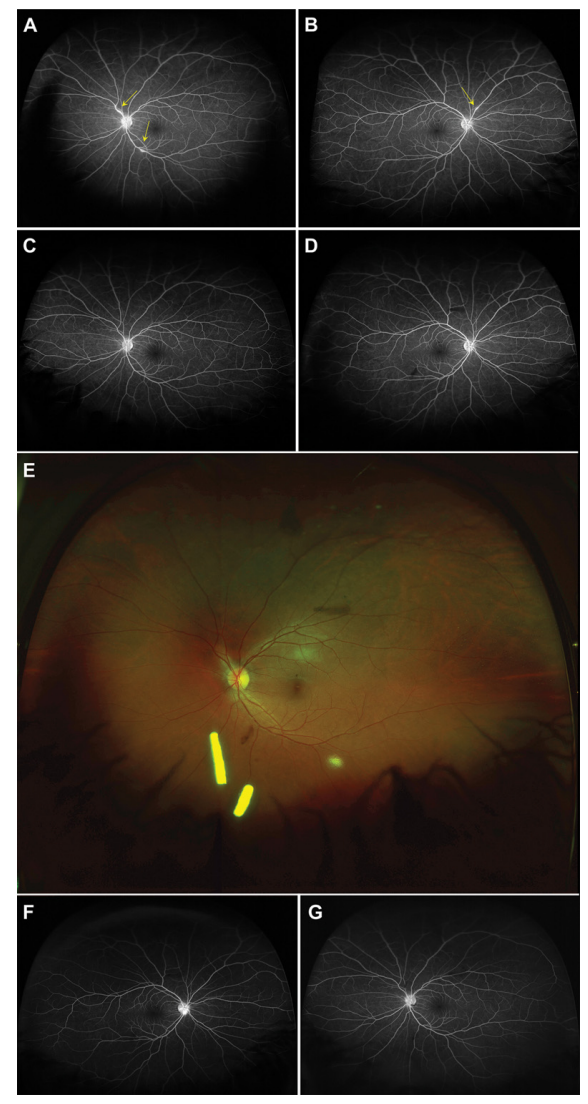

Figure I A) Fluorescein angiography (FA) left eye (OS) of patient I showing persistent leakage of the disc and perivascular leakage (yellow arrows) after treatment with oral prednisone and sub-Tenon's triamcinolone OS. B) FA right eye (OD) showing progression to the fellow eye with leakage of the disc and perivascular leakage (yellow arrow) while on oral prednisone. C-D) FA 4 weeks following the $0.7 \mathrm{mg}$ dexamethasone implantation in both eyes showing resolution of papillitis vasculitis. E) Fundal photography shows the location of the implant in the inferior vitreous base in OS. F-G) FA 4 months following the $0.7 \mathrm{mg}$ dexamethasone intravitreal implant and 6 weeks after finishing oral steroids, showing no recurrence of papillitis or vasculitis in both eyes. 


\section{Patient 2}

A 49-year-old male presented with bullous serous retinal detachments (RD) OU. OCT showed multiple large serous RDs. A work-up was positive for HLA-DR4. A diagnosis of probable Vogt-Koyanagi-Harada (VKH) disease was made. ${ }^{6}$ The patient received 1 sub-Tenon's triamcinolone injection OS with no improvement. Ozurdex was administered OS and oral prednisone $60 \mathrm{mg}$ started. BCVA improved to 20/50 OD and 20/25 OS. For persistent subretinal fluid (SRF) OD, Ozurdex was given. Both eyes developed recurrent SRF after oral prednisone taper. A second Ozurdex implant was given OS and oral prednisone re-started. At final visit 4 months after initial Ozurdex implant, on oral prednisone, BCVA was 20/20 OD and 20/30 OS with no SRF OU.

\section{Patient 3}

A 29-year-old female presented with hand motion vision OS. Examination showed vitritis, papillitis, and vasculitis OS. OCT showed cystoid macular edema (CME). Uveitis work-up was negative; the patient was diagnosed with idiopathic ocular inflammtion. Ozurdex was administered. At 2.5 months post-Ozurdex, BCVA was 20/40 without CME. At 4-month follow-up, OCT showed recurrent CME. A second Ozurdex was given. Four months after the second implant, BCVA was 20/40 with no CME (Figure 2).

\section{Patient 4}

An 81-year-old female presented with recurrent nongranulomatous uveitis OD treated with topical prednisolone.
Uveitis work-up was unrevealing. BCVA was 20/50. Examination showed anterior chamber inflammation. OCT showed CME OD. The patient received Ozurdex. At 1-month follow-up, off of topical steroids, inflammation and CME resolved. BCVA remained 20/50 due to pre-existing cataract. Four months post-implant, inflammation and CME returned; patient deferred further intervention.

\section{Discussion}

In the present series, Ozurdex was able to successfully control inflammation and improve CME in 4 eyes of 3 patients. Two cases failed prior local therapy. The duration of effect of the implant was approximately 3 to 4 months. No patients developed major systemic or ocular side effects, particularly ocular hypertension. However, follow-up time was insufficient to assess cataract formation.

There was recurrence of SRF after oral prednisone taper despite recent Ozurdex implants with probable VKH. There have been a few reports of VKH treatment with intravitreal corticosteroids with mixed results. ${ }^{7-9}$ Thus, systemic treatment remains the mainstay of therapy. However, intravitreal corticosteroids may play a role as adjuvant therapy.

Although the results of phase 3 trial of Ozurdex in noninfectious uveitis have been completed and Ozurdex recently received approval in the United States, this series is, to the best of our knowledge, one of first to report clinical experience with Ozurdex. ${ }^{10}$ Our series confirms that Ozurdex can be effective for treating noninfectious uveitis; however, the durability of that effect was considerably shorter than the 6-month reinjection interval typically utilized in retinal vein
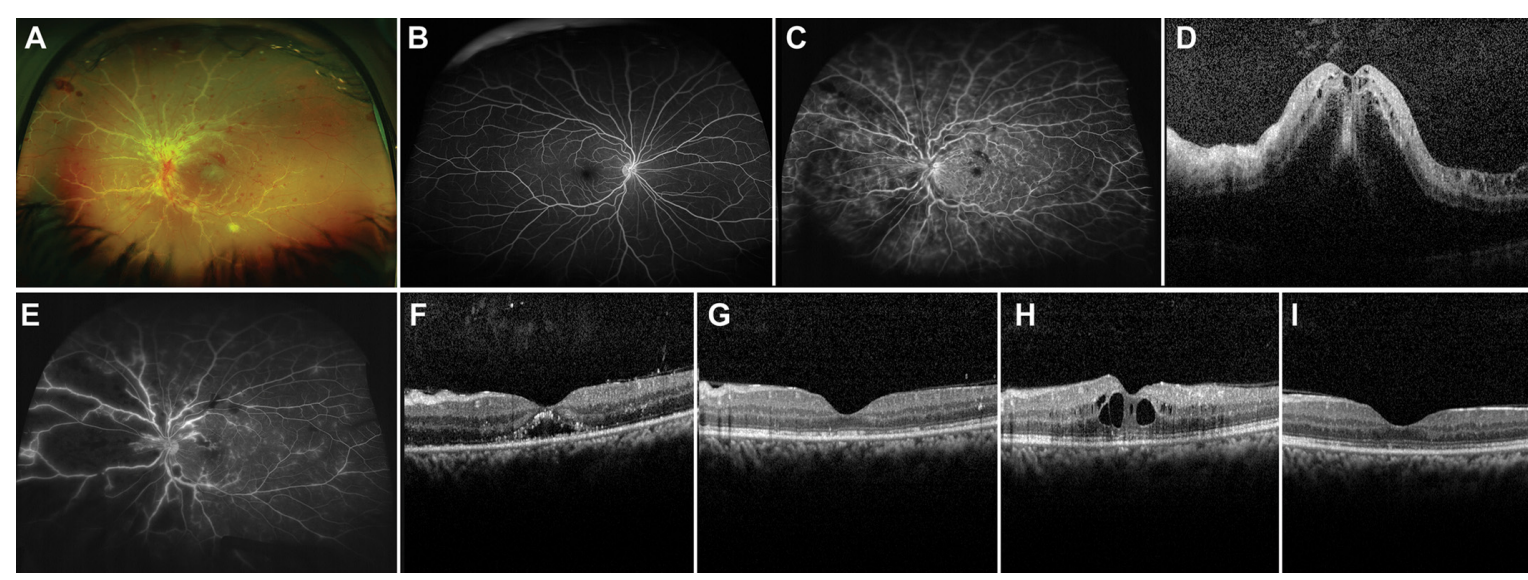

Figure 2 A) Baseline fundal photography left eye (OS) of patient 3 showing vitritis, papillitis and widespread vasculitis with extensive sheathing of the vessels in OS. B) Baseline fluorescein angiography (FA) right eye (OD) showing no evidence of inflammation. C) Baseline FA OS revealed papillitis and considerable vasculitis OS. D) Baseline optical coherence tomography (OCT) OS with cystoids macular edema (CME). E) FA OS II days following the $0.7 \mathrm{mg}$ dexamethasone intravitreal implant showed significantly decreased perivascular, optic disc, and parafoveal leakage, and F) OCT revealed a drastic reduction in CME. G) 2.5 months following implant placement OCT OS showed no recurrence of CME. H) Almost 4 months following implant placement OCT OS showed return of CME. I) Two months after receiving a second dexamethasone implant OCT OS showed resolution of CME. 
occlusion. ${ }^{11}$ Further prospective, controlled studies need to be performed to better determine efficacy, duration of effect, and side effects.

\section{Disclosure}

Dr Szilárd Kiss serves on the Physician Speakers Bureau for Allergan, Inc, Irvine, California. No financial support was received for this study. Drs Jane S. Myung and Grant D. Aaker declare no potential conflicts of interest.

\section{References}

1. van Kooji B, Rothova A, de Vries P. The pros and cons of intravitreal triamcinolone injections for uveitis and inflammatory cystoid macular edema. Ocul Immunol Inflamm. 2006;14:73-85.

2. Goldstein DA, Godfrey DG, Hall A, et al. Intraocular pressure in patients with uveitis treated with fluocinolone acetonide implants. Arch Ophthalmol. 2007;125:1478-1485.

3. Kupperman BD, Blumenkranz MS, Haller JA, et al. Dexamethasone DDS Phase II Study Group. Randomized controlled study of an intraveitreous dexamethasone drug delivery system in patients with persistent macular edema. Arch Ophthalmol. 2007;125:309-317.

4. Williams GA, Haller JA, Kupperman BD, et al. Dexamethasone DDS Phase II Study Group. Dexamethasone Posterior-Segment Drug Delivery System in the treatment of macular edema resulting from uveitis or Irvine-Gass syndrome. Am J Ophthalmol. 2009;147:1048-1054.
5. Haller JA, Kupperman BD, Blumenkranz MS, et al. Dexamethasone DDS Phase II Study Group. Randomized controlled trial of intravitreous dexamethasone drug delivery system in patients with diabetic macular edema. Arch Ophthalmol. 2010;128:289-296.

6. Read RW, Holland GN, Rao NA, et al. Revised diagnostic criteria for Vogt-Koyanagi-Harada disease: report of an international committee on nomenclature. Am J Ophthalmol. 2001;131:647-652.

7. Karacorlu M, Arf Karacorlu S, Ozdemir H. Intravitreal triamcinolone acetonide in Vogt-Koyanagi-Harada syndrome. Eur J Ophthal. 2006;16:481-483.

8. Andrade RE, Muccioli C, Farah ME, Nussenblatt RB, Belfort R. Intravitreal triamcinolone in the treatment of serous retinal detachments in Vogt-Koyanagi-Harada syndrome. Am J Ophthalmol. 2004;137: 572-574.

9. Khalifa Y, Loh AR, Acharya NR. Fluocinolone acetonide intravitreal implants in Vogt-Koyanagi-Harada disease. Ocul Immunol Inflamm. 2009;17:431-433.

10. United States Food and Drug Administration Website. http://www. accessdata.fda.gov/scripts/cder/drugsatfda/index.cfm?fuseaction=Search. DrugDetails. Accessed 2010 Sep 30.

11. Haller JA, Bandello F, Belfort R Jr, et al. OZURDEX GENEVA Study Group. Randomized, sham-controlled trial of dexamethasone intravitreal implant in patients with macular edema due to retinal vein occlusion. Ophthalmology. 2010;117:1134-1146.
Clinical Ophthalmology

\section{Publish your work in this journal}

Clinical Ophthalmology is an international, peer-reviewed journal covering all subspecialties within ophthalmology. Key topics include: Optometry; Visual science; Pharmacology and drug therapy in eye diseases; Basic Sciences; Primary and Secondary eye care; Patient Safety and Quality of Care Improvements. This journal is indexed on

Submit your manuscript here: http://www.dovepress.com/clinical-ophthalmology-journal

\section{Dovepress}

PubMed Central and CAS, and is the official journal of The Society of Clinical Ophthalmology (SCO). The manuscript management system is completely online and includes a very quick and fair peer-review system, which is all easy to use. Visit http://www.dovepress.com/ testimonials.php to read real quotes from published authors. 